\title{
PrevajANJe Ko UnOVE POEZIJE IZ KOREJŠČINE V SLOVENŠČINO
}

\author{
Eva VUČKOVIČ \\ Korea University, Korea \\ eva.vuckovic90@gmail.com
}

\author{
KANG Byoung Yoong \\ Univerza v Ljubljani \\ oddyoong@yahoo.com
}

\section{Povzetek}

Pišem v zrak je zbirka pesmi korejskega pesnika Ko Una, ki je bila avgusta lani prevedena $v$ slovenščino. Zbirka zajema izbrane pesmi, ki jih je pesnik napisal v zadnjih petnajstih letih. Ko Unova poezija je na videz enostavna, a pesmi pogosto vsebujejo skrita sporočila, ki jih avtor želi predati bralcu. Pesmi se dotikajo različnih tem, med njimi najdemo pesmi o naravi, budistične pesmi, pesmi, ki namigujejo na politično situacijo $v$ sodobni korejski družbi, kritiko sodobnega človeka itd. Oblikovanje pesmi kaže na to, da jih Ko Un ne želi postavljati znotraj forme. Verz je svoboden, zdi se tudi, da pesnik ponekod načrtno prelomi verz na dve vrstici, to naredi ravno zato, da kljubuje normam poezije. Zapletene metafore, prepletanje tradicionalnega in sodobnega jezika ter besedne igre so bolj pomembni kot sama oblika pesmi. Nemogoče je našteti vse težave, na katere smo naleteli med prevajanjem zbirke, saj bi morali analizirati vsako pesem posebej, zato smo v tem članku obravnavali le najbolj očitne in največje probleme, ki smo jih imeli pri prevajanju poezije iz korejščine v slovenščino. Večina jih je nastala zaradi strukturnih razlik med korejskim in slovenskim jezikom, veliko pa jih je nastalo tudi zaradi besedišča in kulturnih razlik. Večkrat smo se spraševali, koliko svobode imamo kot prevajalci in do kolikšne mere lahko pesem spremenimo in hkrati obdržimo vse namige, ki jih je pesnik poskušal prenesti bralcu.

Ključne besede: Ko Unova poezija; korejska poezija; prevajalski problemi

\begin{abstract}
Pišem $v$ zrak is a collection of poems by the Korean poet Ko Un, that was translated into Slovene in August of 2016. The collection features a selection of poems written in the last 15 years. Ko Un's poetry appears simple, however, there are often deeper messages hidden within the verses. His subjects are diverse and embrace such themes as nature, Buddhism, as well as allusions to the political situation of the modern Korean society, and criticism of the modern man. From the structure of his poems, it seems that Ko Un does not want to use any formalism in his work. He uses free verse and sometimes even breaks the verse into two lines, just to defy the set norms of poetry. Complex metaphors, intertwining of the traditional and modern language, and wordplay take
\end{abstract}


precedence over the form. To list all the problems that occurred in the process of translating would be an impossible undertaking, since it would have to include an in-depth analysis of each separate poem. Therefore, this article addresses only the major and most obvious problems we have encountered when translating poetry from Korean into Slovene. The majority of problems arose due to the difference in the structure of both languages and many due to the vocabulary and cultural differences. The essential dilemma was how much freedom we have as translators, and to what extent we are allowed to alter a poem without ignoring the gist the author intends to convey to readers.

Keywords: poetry of Ko Un; Korean poetry; translation problems

\section{Uvod}

V prispevku predstavljamo problematiko prevajanja poezije iz korejščine v slovenščino, na primeru prevoda zbirke pesmi korejskega avtorja Ko Una, ki je v slovenščini izšel pod naslovom Pišem v zrak. Prevod je izbor pesmi iz različnih pesnikovih zbirk in je delo treh prevajalcev ${ }^{1}$.

Pri prevajanju korejske poezije smo se soočali z nemalo težavami. Poezija Ko Una je včasih zelo preprosta (predvsem njegove kratke pesmi), včasih pa, zaradi dolgih večstavčnih povedi, metafor in besednih iger, precej zapletena. Korejščina je sama po sebi zelo drugačna od slovenščine, zato smo morali prevajalci upoštevati, da $v$ slovenččini dostikrat ne moremo doseči enakih učinkov, kot jih je pesnik lahko $v$ originalni različici, oziroma moramo za podobne učinke poseči po drugih jezikovnih sredstvih. Pred prevodom smo temeljito analizirali vsebino in strukturo pesmi pregledali smo rimo, ritem, pa tudi pomen in značilnosti pesmi Ko Una. Hkrati smo pregledali prevode njegovih pesmi $v$ nekaterih drugih evropskih jezikih (na primer $v$ angleškem in francoskem, $v$ zbirkah ali na medmrežju). Odločili smo se, da se ne bomo naslanjali na druge prevode, kljub temu pa so bili včasih $v$ veliko pomoč, saj so nam služili kot dokaz, da zaradi razlik med jeziki nekaterih stvari ne moremo prevesti, kot bi radi.

Ker je Ko Unova poezija zelo zaznamovana z njegovo življenjsko zgodbo, bomo v članku najprej na kratko predstavili pesnikovo življenje in delo. Nadaljevali bomo s predstavitvijo razlik med korejščino in slovenščino, ki so bistveno vplivale na prevajalske odločitve. Preučili bomo slog pesnika in poudarili nekatere značilnosti njegove poezije, posvetili se bomo vsebini pesmi in na koncu omenili nekatere konkretne težave, s katerimi smo se srečali med prevajanjem.

\footnotetext{
${ }^{1}$ Delo smo prevedli Byoung Yoong Kang, Aleš Šteger in Eva Vučkovič.
} 


\section{Ko Un - življenje in delo}

Ko Un se je rodil leta 1933 v današnji Južni Koreji, ki je bila takrat pod okupacijo Japonske. Raba korejščine je bila prepovedana, zato se je Ko Un naučil brati in pisati korejsko s pomočjo kmeta iz njegove vasi. Pri dvanajstih letih je ob cesti našel knjigo korejskega pesnika Han Hauna. Nad njegovo poezijo je bil tako navdušen, da se je odločil postati pesnik. Ko se je začela korejska vojna (1950-1953), je bil Ko Un presuh, da bi ga vpoklicali, vseeno pa je občutil grozo vojne, saj je moral pokopavati trupla padlih vojakov. Med vojno ni mogel razmišljati o pesniškem poklicu. O smrti in vojni pove: „Kaj je smrt? Ali ni le praznina brez življenja? /.../ Nekega dne je naenkrat utihnil smeh prijatelja, s katerim sva se skupaj podila okoli, in vse, kar je na tem svetu imelo smisel, je postalo nesmiselno. Nemogoče je bilo, da bi takrat sanje pesnika našle svoje mesto pod soncem." (Ko Un, 2016, str. 253)

Vojna mu je pustila hude posledice, zato je uteho poiskal $v$ budizmu in postal budistični menih. Po desetih letih je izstopil iz budističnega reda in se spopadal s hudo nespečnostjo. Večkrat je poskušal storiti samomor. V 60-ih letih prejšnjega stoletja je na oblast prišel Park Chung-hee, ki je s silo vladal do leta 1979. Življenjski pogoji so bili slabi. Nekega dne je Ko Un na tleh pivnice našel časopis, v katerem je prebral članek o smrti tovarniškega delavca Jeon Tae-ila, ki je $v$ znak protesta zaradi slabih delovnih pogojev naredil samomor s samovžigom. Ko Una je ta dogodek predramil. Začel se je zanimati za krivice, ki so se dogajale okoli njega, postal je angažiran umetnik. Zaradi svojega delovanja je bil večkrat zaprt. O življenju v zaporu pravi: "Zaporniške celice so spominjale na tunele v mravljišču, zato nismo mogli vedeti, kje je kdo. Vojaška policija nas je nadzorovala, rešetk ni bilo; ko so ugasnili 30-vatne žarnice, smo se znašli v popolni temi. Preživel sem lahko le tako, da sem razmišljal, kako bom ob smrti kričal: 'Združitev, demokracija,' ali pa bom recitiral kratke pesmi« (Ko Un, 2016, str. 259). Takrat se je odločil, da bo, če bo kdaj izpuščen, napisal pesem o vsakem človeku, ki ga je kdaj srečal. Leta 1982 je, končno na svobodi, začel pisati svoje prvo obsežnejše delo Deset tisoč duš (만인보, man-inbo). Delo obsega 15 zvezkov, pesnik pa je napisal več kot 3000 pesmi o ljudeh, ki jih je srečal. Hkrati se v tem delu že vidi Ko Unov slog, ki ga Peter H. Lee opiše kot: »Bistroumnost, sleng, dialekti, pregovori, kletvice, vzdevki, prizori in vedênje, vzkliki, nagovori rastlin, krajev in predmetov - vse to krasi Deset tisoč duš" (Lee, 2003, str. 453).

Do danes je Ko Un objavil več kot 150 del, je "gora poezije« (Génetiot, 2016, str. 36), njegova dela so prevedena v več kot 20 jezikov. Je eden od najbolj pomembnih predstavnikov sodobne korejske literarure, večkrat pa je bil tudi nominiran za Nobelovo nagrado za literaturo. 


\section{Nekaj značilnosti korejščine}

Korejščino danes umeščamo med altajske jezike. Dolga leta je niso hoteli uvrstiti nikamor, saj je bila od ostalih jezikov tako drugačna. Eden prvih, ki je korejščino na koncu le uvrstil med altajske jezike, je bil finski jezikoslovec Gustaf John Ramstedt. Med altajske jezike poleg korejščine uvrščamo tudi mongolske, turške in tunguškomandžurske jezike. Zaradi dolge skupne zgodovine korejščino povezujemo tudi s kitajščino in japonščino, čeprav naj ti trije jeziki ne bi pripadali isti jezikovni skupini.

Korejščino zapisujemo s korejsko abecedo hangeul (한글, ki so jo začeli uporabljati leta 1443 , ko je bil na oblasti kralj Sejong. Pred tem so za zapisovanje uporabljali kitajske pismenke; ker pa je bil ta sistem pisanja za večino prebivalstva težak, se je kralj Sejong odločil, da bo zapisovanje poenostavil in je zato izumil enostavno abecedo. $\mathrm{S}$ tem je med ljudmi dosegel večjo pismenost.

Ko govorimo o strukturi korejskega jezika in strukturi povedi, moramo poudariti, da je struktura korejščine precej drugačna od slovenščine. Slovenščina pripada skupini indo-evropskih jezikov, povedi večinoma zapisujemo v zaporedju osebek - povedek predmet. Tako kot v japonščini, postavljamo v korejščini predikat na konec povedi, vsi drugi členki (angl. particles) pa stojijo za elementom, na katerega se nanašajo (Sohn, 1999, str. 15). Ponavadi torej sledimo zaporedju osebek - predmet - povedek. Lahko bi rekli, da je vrstni red besed v slovenščini precej svoboden. Glede na pomen, besedo, ki jo želimo poudariti, ali pa glede na slog, lahko vrstni red besed zamenjamo. Tudi korejččina do neke mere dovoljuje svobodno izbiro vrstnega reda besed, vseeno pa, kot rečeno, precej strogo sledi pravilu, da se povedek postavlja na konec povedi. Pri prevajanju pesmi je besedni red zelo pomemben, vendar pa se mora prevajalec zavedati, da pri prevajanju iz korejščine $v$ slovenščino ne bo mogel vedno slediti enakemu vrstnemu redu besed, kot je $v$ originalu. Marsikdaj bo moral vrstni red popolnoma obrniti in $\mathrm{s}$ tem bo morda izgubil rimo ali ritem. Če želi obdržati smisel, drugače ne bo šlo. Ob pregledu prevodov $v$ druge evropske jezike lahko vidimo, da so se tudi drugi prevajalci morali zateči k podobnim odločitvam.

Pri rabi korejskega jezika se moramo zavedati, da se v korejščini, izraziteje kot v evropskih jezikih, skozi jezik izraža odnos govorca do poslušalca. Govorec z uporabo glagolskega obrazila pokaže, kakšen odnos ima do poslušalca, z različnim glagolskim obrazilom (v angleščini "sentence ender", gl. Sohn Ho-Min, 1999, str. 355, za primerjavo z japonščino, gl. Bekeš, 2000, str. 37) pa lahko doda povedi tudi drugačen pomen. Avtorica knjige The routledge course in Korean translation primerja korejščino $\mathrm{z}$ angleščino in pravi: "V nasprotju $\mathrm{z}$ angleščino se korejščina veliko bolj osredotoča na dinamiko odnosa med govorcem in poslušalcem. $V$ angleščini lahko govorec reče: 'Dežuje,' in s tem ne poda nikakršnega podatka o odnosu med obema udeležencema v interakciji. $\vee$ korejščini pa govorec ne more uporabiti niti najpreprostejših stavkov, kot 
je: 'Dežuje', ne da bi pri tem razkril delovanje odnosa v dani situaciji« (Kiaer, 2017, str. 11).

Nadaljuje s še nekaj konkretnimi primeri, s katerimi pokaže, kako se pomen povedi spremeni glede na uporabljeno glagolsko obrazilo (v slovenščino bi vse naštete primere lahko prevedli z »Dežuje« ali pa (še bolj dobesedno) »Dež pada«):

바가 온다, biga onda. (Govorec opisuje v preprostem in nevtralnem tonu ali pa izraža rahlo presenečenje.)

바가 오네, biga one. (Govorec govori sam s seboj. Gre za poudarjalno glagolsko obrazilo, ki je pogosto v samogovorih in poeziji.)

바가 오는구나, biga o-neun-guna. (Govorec izraža presenečenje. Tudi to glagolsko obrazilo je lahko poetično.)

/.../

바가옵니다, biga obnida. (Govorec opisuje situacijo v formalnem slogu.)« (Kiaer, 2017, str. 11).

Tudi rabe jezika se moramo pri prevajanju zavedati. Ko Un pri svojih pesmih uporablja zelo različne glagolske oblike, slovenščina pa takih značilnosti nima, zato smo pri prevajanju marsikdaj morali poseči po drugih sredstvih, da se pomen ni izgubil oziroma spremenil.

\section{Ko Unov slog}

Zbirka pesmi, ki smo jo prevedli, zajema Ko Unove pesmi, napisane v zadnjih dvajsetih letih. Pesmi so med seboj zelo različne. Nekaj je kratkih tri- ali štirivrstičnic, ki delujejo kot trenutki ali vtisi, ujeti v času. V svojem članku Park Byoungkook pravi o kratki poeziji Ko Una: „Nekatere izmed Ko Unovih kratkih pesmi se sprva zdijo razdrobljene ali pa celo plehke, a bralce besedila pogosto pritegnejo in jih preberejo ponovno - pri čemer se jim razkrije cela vrsta razodetij, ki pričarajo nasmešek ali celo nenaden glasen smeh« (Park, 2015, str. 81-82).

V zbirki prevedenih pesmi najdemo tudi daljše pripovedne pesmi - npr. pesem Misli zadnjih dni, ki govori o Ko Unovi izkušnji tradicionalne pripovedne poezije, kot jo je pridobil med svojim potovanjem po Mongoliji.

Rima in verz $v$ Ko Unovi poeziji sta svobodna. Korejski jezik postavlja glagol na konec stavka, oblika glagola pa je odvisna npr. od stopnje vljudnosti oz. od tega, kakšen pomen želi govorec dati stavku. Pri pesmih se zato velikokrat pojavlja enaka končnica na koncu stavka ali povedi, kar daje vtis ponavljajoče se rime, hkrati pa tvori ritem. Toda Ko Un ne želi upoštevati jezikovnih norm. Zdi se, da namerno razdeli stavke in jih napiše 
v dveh ali treh vrsticah, včasih v eno vrstico napiše le eno besedo, kot bi se s strukturo jezika poigraval. Ko Un pravi:

॥I have composed a few set-form poems in Chinese characters, quatrains with four linesof seven characters. Apart from them, I have never composed even a single sijo (a fixed-form Korean-language poem), refusing to spply any kind of methodological order to the external form of my poems. If poetry is a matter of thinking with images, well, that is surely one possible kind of system, but in some cases my poetry shuddered at its own rhythms and hurried to demolish them. When strict rules requiring regular form were imposed on classical Chineselanguage poems like government regulations, I became a rebel. Fundamentally the poet remains free within the living structure known as a poem « (Ko Un, 2008b, str. 36).

"Spesnil sem nekaj pesmi v stalnih oblikah s kitajskimi pismenkami, štirivrstičnice s po sedem pismenkami v vsaki vrstici. Razen teh nisem nikoli spesnil niti ene same sijo pesmi (stalna pesniška oblika v korejščini), ker zunanji obliki svojih pesmi ne želim vsiljevati kakršnegakoli metodološkega reda. Če poezija zadeva razmišljanje v slikah je to zagotovo en možen sistem, vendar pa je v nekaterih primerih moja poezija drhtela že ob lastnem ritmu in ga kaj hitro podrla. Ko se je bila klasična poezija v kitajščini prisiljena podrediti strogim vladnim pravilom glede oblike, sem postal upornik. V osnovi ostane pesnik svoboden znotraj živeče strukture, ki jo poznamo kot pesem.« (Ko Un, 2008b, str. 36, prevedla avtorja).

Prav tako ne uporablja ločil, kot da bi želel, da so njegove pesmi popolnoma svobodne. Ko Un torej želi, da pesem sledi svojemu notranjemu ritmu, ki ni zgrajen na podlagi rime ali na podlagi števila zlogov $v$ verzu. Če bi na internetu pogledali videoposnetke, na katerih Ko Un bere svojo poezijo, bi takoj ugotovili, da dostikrat namerno ne sledi napisanemu besedilu, saj včasih določeno besedo večkrat ponovi, drugič besedo izpusti. Zdi se, da njegova poezija postane živa skozi branje in da ni tako pomembno, da sledimo napisanemu besedilu, bolj pomemben je način, kako je pesem prebrana. Angleški prevajalec njegove poezije, Brother Anthony of Taizé, je o tem povedal:

»Kamorkoli je šel, je pustil globok vtis, še posebej, ko je prebiral svoje pesmi v raskavem, napetem, dramatičnem tonu, ki mu je ljub. Zdi se, da dejstvo, da večina poslušalcev ni razumela niti besede, na dojemanje besedila ni imelo nikakršnega vpliva. Angleščine ni vešč, vendar se je vedno znova vzpostavil globok stik, še preden je kdorkoli bral angleške prevode ali povzetke tega, kar je govoril. Bojim se, da so bili prevodi po njegovem dramatičnem nastopu precej pusti.« (Brother Anthony of Taizé, 2000).

Ko Un želi z neupoštevanjem jezikovnih pravil in norm pustiti pesmim jezikovno svobodo, želi, da njegove pesmi dobijo končno podobo šele skozi interpretacijo. $V$ svoji poeziji se bolj osredotoča na prepletanje tradicionalnega in sodobnega jezika, na zapletene metafore, kot pa na jezikovne oblike in formalnosti. 


\section{Vsebina pesmi}

Pri prevajanju je zelo pomembno, da prevajalec dobro razume vsebino vsake pesmi, kar mu pomaga pri izbiri ustreznega besedišča in s tem omogoči boljši prenos sporočila iz enega jezika $v$ drugega. $V$ svojih pesmih Ko Un piše o številnih temah, še posebej o tistih, povezanih z njegovim življenjem. V njih razkriva položaj današnje korejske družbe, včasih razgalja politične značilnosti družbe, ki jih pogosto skriva za metaforami iz narave. Ko Una je močno zaznamovala korejska vojna, takrat je izgubil družino in prijatelje, Koreja je bila opustošena, hrane ni bilo. Dolga leta ni mogel preboleti grozot, ki so se takrat dogajale. $V$ svojih pesmih zato velikokrat omenja vojne, ki se še vedno dogajajo na svetu. Take so na primer pesmi Nedavno priznanje (촤근의고백 choe-geunui gobaeg), Črta začasnega premirja (휴전선, hyujeonseon), Dom (집 jib) in Imeti dvajset let (스무, seumusal).

Dotika se zgodovinskih in političnih tem. Bleiker in Hundt na kratko povzemata nekatere dogodke korejske zgodovine, ki so pesnika še posebej zaznamovali in se zato pojavljajo $\mathrm{v}$ mnogih pesmih:

"The underlying political significance of Ko Un's poems lies in their search for a critical notion of Korean identity. During the various stages of Ko Un's life Korea faced challenges that at times took on a deep existential nature: a long and oppressive colonial occupation by Japan /.../; a division of the country into a communist North and a capitalist South; a devastating civil war /.../; a rapid industrialization process in the South, driven by several authoritarian regimes; and the still ongoing residues of national division and corresponding security threats" (Bleiker \& Hundt 2010, str. 332).

»Globlji politični pomen Ko Unovih pesmi leži v njihovem iskanju kritičnega pojmovanja korejske identitete. $V$ različnih obdobjih njegovega življenja se je Koreja soočala z izzivi, ki so bili pogosto eksistenčne narave: z dolgotrajno japonsko kolonialno okupacijo, /.../; z ločitvijo države na komunistični sever in kapitalistični jug; z uničujočo državljansko vojno /.../; s hitro industrializacijo juga pod vodstvom avtoritarnih režimov; z ostanki narodne delitve in s tem povezanimi grožnjami.« (prevod: avtorja).

Ko Un mnogokrat opeva 'staro Korejo', Korejo, v kateri je preživel mladost, a se je do sedaj popolnoma spremenila. Taki sta na primer pesmi Le kam so šle vse moje meje (내 변방은 어디 갔다, nae byeonbang-eun eodi gass-da) in Žalovanje (한탄, hantan). V pesmih lahko najdemo kritiko sodobnega človeka in sodobne družbe, taka je pesem Žalost, prvoosebno $v$ ednini (일인칭은 슬프, il-in-ching-eun seulpeuda). Pogosto se dotakne tudi budizma, saj je 10 let preživel kot budistični menih in ga je to obdobje precej zaznamovalo - na primer v pesmih Nekega dne (어느, eoneu nal) in Duša (넉، neogs). Piše pa tudi o sami poeziji, o tem, kaj je pesem in kdo je pesnik - pesmi Pesem (시 si) in Čas z mrtvimi pesniki (죽은시인들과의사간, jug-eun si-indeulgwa-ui sigan). 


\section{Nekaj konkretnih prevajalskih problemov}

$V$ tem članku bo nemogoče omeniti vse prevajalske težave, s katerimi smo se srečali med prevajanjem. Če bi to želeli narediti, bi morali podrobno analizirati vsako pesem posebej. Težav nam ni delala le struktura slovenskega jezika, ki je povsem drugačna od korejskega, ampak tudi dejstvo, da smo prevajali poezijo, ki še posebej temelji na jeziku; na izbiri besed in na strukturi jezika.

Omeniti moramo tudi kulturne razlike, ki so oteževale prevajanje. Ko smo na založbi tik pred izdajo popravljali še zadnje podrobnosti, so nas, na primer, pri pesmi Pomladni dan mineva (봄날은간다, bomnal-eun ganda) opozorili na verz »morske plošče, podobne babičini pahljači« (»오할머니 부채 같은 가자 $k_{k}$, oehalmeoni bu-chae gat-eun gajami) in vprašali, ali ni ta verz nekoliko nenavaden in se ni morda zgodila napaka pri prevajanju. Le kako bi riba spominjala na pahljačo? V mislih so imeli zložljivo pahljačo, ki je pri nas najbolj pogosta. Tudi v Koreji poznajo zložljivo pahljačo, Ko Un pa je imel v mislih verjetno korejsko tradicionalno pahljačo, ki po obliki spominja na obliko morske plošče (vrsta ribe). $S$ tem vprašanjem so opozorili na to, da je pri prevajanju (poleg strukture jezika, slovnice in besedišča) pomembno upoštevati tudi vse kulturne razlike, saj drugače bralci prevoda ne bodo razumeli.

\subsection{Ločila}

Prva stvar, ki jo opazimo takoj, ko odpremo Ko Unovo zbirko pesmi v korejščini, je, da Ko Un ne uporablja ločil. Redko doda klicaj ali piko na koncu povedi. V slovenskem prevodu smo se odločili, da bomo uporabili ločila in veliko začetnico (ki v korejččini ne obstaja), saj je raba ločil v slovenskem jeziku zelo pomembna in nam pesmi pomaga lažje razumeti. Če na začetku stavka ne bi uporabili velikih črk, bi mnoge pesmi postale dvoumne, saj bi bilo težko razlikovati, kaj se nanaša na določen verz, katera dva verza je treba brati skupaj in katere verze je potrebno ločiti. Ločila nam pomagajo tudi pri določevanju ritma pesmi.

V ilustracijo dve sliki pesmi v korejščini in slovenskem prevodu. 
임종

바다야

네 3천년 앞에 서면

내 몸속 속속들이 내면 일체가

몽땅 사라져버릴 터

배고프다

배고프다

온통 외부이다

Slika 1: Pesem v korejščini

Smrt

Morje,

ko stojim pred tvojimi tri tisoč leti

celotna notranjost mojega telesa

popolnoma izgine.

Lačen sem!

Lačen sem!

Vse, kar ostaja, je zunaj mene.

Slika 2: Pesem v slovenskem prevodu

\subsection{Ritem in rima}

Ko govorimo o ritmu, ne moremo mimo strukture obeh jezikov. $V$ korejščini je, podobno kot $v$ japonščini, »odvisnik $v$ neformalni obliki enostavno postavljen pred samostalnik, ki ga modificira /.../ Obratno kot v slovenščini, kjer oziralni odvisnik stoji za samostalnikom)« (Bekeš, 2000, str. 111). Bekeš nadaljuje in pove, da temu odvisniku pravimo "prisamostalniški (adnominalni) odvisnik.» 
Ko Un v svojih pesmih pogosto konča verz s samostalnikom (v spodnjem primeru je to samostalnik 'mesto', 곳, gos), pred njim pa doda prisamostalniški odvisnik. Ker se samostalnik na koncu verza ponavlja, to omogoča ustvarjanje nekakšne rime. Primer tega je pesem Le kam so šle vse moje meje (내변방은어디갰나, nae byeonbang-eun eodi gass-na):

$\begin{array}{lll}\text { 서러웠던곳 } & \text { seoleo-woss-deon gos } & \text { Mesto nesreče. } \\ \text { 어디서도 먼 곳 } & \text { eodiseodo meon gos } & \text { Mesto, daleč proč od vsega. } \\ \text { 못 떠나는 곳 } & \text { mos tteonaneun gos } & \text { Mesto, ki ga je težko zapustiti. } \\ \text { 못 떠나다 } & \text { mos tteonada } & \text { Zapustiti. } \\ \text { 못 떠나다 } & \text { mos tteonada } & \text { Zapustiti! } \\ \text { 기어이 떠나는 곳 } & \text { gi-eo-i tteonaneun gos } & \text { Mesto, ki ga zapuščamo. } \\ & & \\ \text { 내 마음의 개펄 바닥 } & \text { nae ma-eum-ui gaepeol badag } & \text { Mesto, kjer vzcveti šipek } \\ \text { 해거리 명자꽃이 } & \text { haegeoli myeongja-kkoch-i } & \text { vsaki dve leti } \\ \text { 똑똑하던 곳 } & \text { ttogttoghadeon gos } & \text { srca. } \\ 10 \text { 년 전과 } & \text { sib nyeon jeon-gwa } & \text { Mesto, ki je pred desetimi leti } \\ 10 \text { 년 후가 같았던 곳 } & \text { sib nyeon huga gat-assdeon gos mojega }\end{array}$

V slovenščini smo morali samostalnik 곳 (gos, mesto, kraj), ki je nosilec pomena, postaviti na začetek povedi, saj se drugače pesmi ne bi dalo prevesti. Če bi v slovenskem jeziku spremenili besedni red, bi bil končni izdelek čuden in umeten, morda celo nesmiseln. S spreminjanjem besednega reda smo izgubili strukturo korejskega verza; na žalost moramo včasih žrtvovati obliko, da ohranimo smisel in sporočilo.

\subsection{Besedišče}

Eden glavnih problemov, s katerimi smo se srečali pri prevajanju pesmi, je bilo besedišče. Velikokrat se je zgodilo, da nismo mogli najti primernega prevoda. Ustrezen prevod je bilo težko najti, predvsem v primerih, ko je imela beseda v izvirnem jeziku več pomenov ali konotacij, $v$ ciljnem jeziku pa le enega. Velikokrat se je zgodilo tudi, da slovenščina ni imela primernega izraza za nekatere stvari, kar se ponavadi zgodi zaradi kulturnih razlik. Takšna je bila pesem Pomladni dan mineva (봄날은 간다 bomnal-eun ganda), kjer Ko Un navaja različne vrste morskih bitij, ki jih je zlahka najti v Koreji, so del vsakdanjega življenja Korejcev, medtem ko jih v Sloveniji sploh ne poznamo. 


\begin{tabular}{|c|c|}
\hline 봄날은간다 & bomnal-eun ganda \\
\hline 이렇게다주어버려라 & i-leoh-ge da ju-eobeo-lyola \\
\hline 꽃들지고 있다 & kkoch-deul jigo iss-da \\
\hline 이렇게다놓이버려라 & i-leohge da noh-abeo-lyeola \\
\hline 저녁 바다썰물야무도 붙들지 & jeonyeog bada sseolmul \\
\hline 않는다 & $\begin{array}{l}\text { amudo butdeulji anh- } \\
\text { neunda }\end{array}$ \\
\hline 바다층층 & bada cheung-cheung \\
\hline 해피리 & haepali \\
\hline 주치 & jwi-chi \\
\hline 감성돔 & gamseong-dom \\
\hline 멍게 & meong-ge \\
\hline 우럭 & u-leog \\
\hline 광어농어 & gwang-eo nong-eo \\
\hline 세고시 & se-kkosi \\
\hline 오할머니부채같은가지미 & $\begin{array}{l}\text { oehalmeoni bu-chae gat-eun } \\
\text { gajami }\end{array}$ \\
\hline 그이래층말마잘의삶이있다 & $\begin{array}{l}\text { geu a-lae-cheung malmijal-ui } \\
\text { salm-i iss-da }\end{array}$ \\
\hline 삶이란누누이어느 죽음의 & salm-i-lan nu-nu-i eoneu \\
\hline 다음이라고 & jugeum-ui da-eum-ilago \\
\hline 말할나위도 없이 & malhal na-wido eobs-i \\
\hline 지상에더많은 죄지어아겠다 & $\begin{array}{l}\text { jisang-e deo manh-eun joe } \\
\text { ji-eo-yagess-da }\end{array}$ \\
\hline 봄날은간다 & bomnal-eun ganda \\
\hline
\end{tabular}

Pomladni dan mineva

Predaj vse:

rože odcvetajo.

Vse zapusti:

nihče ne zmore zadržati

večerne oseke.

Sloji morja:

meduze,

balestre,

špari,

kozolnjaki,

škarpene,

morski listi, japonski

brancini,

barakude,

morske plošče, podobne

babičini pahljači,

in čisto na dnu morske

vetrnice.

Po smrti se življenje začne znova.

Tega ni treba ponavljati.

Na Zemlji bi moralo biti več grehov.

Pomladni dan mineva.

Naslednji primer najdemo v pesmi Nek nasvet (한충고, han chung-go), ki vključuje verz »Pesem, pesem, modra pesem!« (»시야 시야파랑시야, siya siya palang siya). Gre za besedno igro, saj je korejska beseda za "pesem" (시 si) podobna besedi za "ptico" (새, sae). $V$ verzu nas spominja na verz iz korejske ljudske pesmi, ki bi ga v slovenščino prevedli kot »Ptica, ptica, modra ptica«. Ljudska pesem se nanaša na kmečko revolucijo in sporočilo Ko Una je, da bi morala obstajati revolucija poezije. Ta podatek je zelo pomemben za razumevanje pesmi, zato smo pri prevodu vključili pojasnilo o tem $v$ opombi.

V pesmi Čas z mrtvimi pesniki (죽은 시인들과의 사간, jug-eun si-in-deulgwa-ui sigan) najdemo verz »Življenja mrtvih pesnikov so se ugnezdila v nas kot mit o bitjih, ki se izležejo iz jajca« (» 죽은 시인의 남은 생애가 우리 각자의 난생설회의 생애 가운데 지리잡았기 때문읻k , jug-eun si-in-ui nam-eun saeng-ae-ga u-li gagja-ui nansaengseolhwa-ui saengae ga-unde jalijabass-gi ttaemun-ida). Slovencem je verz verjetno težko razumeti, saj takih mitov skoraj ne poznamo. $V$ korejski mitologiji pa so se skoraj vsi ustanovitelji antičnega korejskega kraljestva izlegli iz jajca. S tem so Korejci želeli pomembnim osebam v korejski mitologiji pripisati nekakšno božansko značilnost. Pri prevajanju bi 
morda lahko poiskali kaj, kar bi se dalo primerjati na primer z grško ali rimsko mitologijo, ki sta slovenskemu bralcu bližji, a bi s tem ponovno izgubili avtentičnost, zato smo se odločili pomen obdržati.

\section{Zaključek}

V tem članku smo poskušali predstaviti nekatere težave prevajalskega procesa pri prevajanju Ko Unovih pesmi iz korejščine v slovenščino. Pri prevajanju poezije moramo nameniti posebno pozornost izbiri besed, ritma in rime, poleg tega pa moramo zagotoviti, da sporočilo ostane čim manj spremenjeno. Pesmi Ko Una se včasih zdijo preproste, po podrobni analizi pa lahko odkrijemo številne skrite ideje ali sporočila, ki jih Ko Un želi predati bralcu. Čeprav se zdi, da je njegova poezija preprosta in enostavna za prevajanje, saj ne upošteva jezikovnih pravil in norm, Ko Un pogosto uporablja zelo zapletene metafore, ki jih je težko razumeti in še težje prevesti. Verjetno ne bomo nikoli dosegli konca pri prevajanju poezije, vedno lahko najdemo nove možnosti, ki bi izboljšale prevod. Kljub vsemu smo želeli s tem člankom predstaviti nekaj primerov in razkriti nekatere težave, s katerimi smo se soočali med prevajanjem Ko Unove poezije. Vsekakor upamo, da bomo z različnimi seminarji in konferencami o prevajanju ter z izmenjavo znanja o korejski in slovenski literaturi $v$ prihodnosti dosegli še boljše prevode.

\section{Acknowledgments}

This work was supported by Seed Program for Korean Studies through the Ministry of Education of the Republic of Korea and Korean Studies Promotion Service of the AKS (AKS-2015-INC-2230013).

\section{References}

Bekeš, A. (2000). Prvi koraki, sodobna japonska slovnica za začetno stopnjo. Ljubljana: Filozofska fakulteta.

Bleiker, R., \& Hundt, D. (2010). Ko Un and the Poetics of Postcolonial Identity. Global Society, 24(3), 331-349.

Brother Anthony of Taizé (2000). Cross-Cultural Communication: Translating Ko Un. Pusan National University. Dostopano na: http://hompi.sogang.ac.kr/anthony/articles/KoUnTranslation.htm.

Génetiot, A. (2012). Ko Un, une vie en poésie. Po\&sie, Corée 2012. N 139-140, 36-41.

Hundt, D. (2008). Poetry in motion: Ko Un and Korean democratization. V Profiles in courage: political actors \& ideas in contemporary Asia (str. 43-54). North Melbourne: Australian Scholarly Publishing. 
Kiaer, J. (2017). The Routledge course in Korean Translation. New York: Routledge.

Ko, Un (2002a). Dugo on si: Ko Un sijib 두고 온 사 고은 시집 Seul: Chang-jag-gwa bi-pyeong-sa 창작과비평사.

Ko, Un (2002b). Neuj-eun nolae: Ko Un sijib 늦은 노래 고은시집 Seul: Min-eumsa 민음사.

Ko, Un (2004). Sous un poirier sauvage. Circé, Belval, France.

Ko, Un (2008a). Heogong: Ko Un sijib 허공. 고은시집 Paju: Chang-bi 창비,

Ko, Un (2008b). Songs for Tomorrow. Los Angeles: Green Integer Books.

Ko, Un (2011). Nae byeonbang-eun eodi gass-na 내변방은어디갔나. Paju: Chang-bi 창비

Ko, Un (2012). First Person Sorrowful. Northumberland: Bloodaxe Books.

Ko, Un (2016). Fleurs de l'instant. Éditions Circé, Belval, France.

Ko, Un (2016). Pišem v zrak. Ljubljana: Beletrina.

Ko Un Poems, Poem Hunter. (2017). Dostopano na: https://www.poemhunter.com/ko-un/poems/.

Lee, P. H. (2003). A History of Korean Literature. Cambridge University Press, Cambridge.

Park, B. (2015). What? Translating the Meditative Poems of Ko Un: Pointed and Witty Shortline Lyrical Poetry. Translation Review, 93(1), 81-87.

Sohn, H. (1999). The Korean language. Cambridge: Cambridge University Press. 